- residents and staff of facilities for persons with intellectual disabilities;

— inmates and staff of correctional facilities;

- health care workers;

- embalmers;

— staff of emergency departments and services.

\section{PREVENTING SPREAD}

To prevent the spread of hepatitis B infection:

- use condoms if you are having sex with new sexual partners or with partners infected with hepatitis B;

- if you are pregnant, you should have a blood test for hepatitis B; infants born to hepatitis B infected mothers should be given hepatitis B immunoglobulin and vaccine within 12 hours after birth;

- do not share injecting equipment;

- do not share personal items that may have blood on them, (for example, razors or toothbrushes);
- if having a tattoo or your body pierced, make sure that the practitioner uses disposable and sterile equipment.

If you are infected:

- do not donate blood, organs or tissue if you have hepatitis $\mathrm{B}$;

- advise your doctor and dentist that you are infected;

- be very careful to make sure that other people are not exposed to your blood or body fluids. Clean up any spills with a paper towel and clean thoroughly with detergent and water until no obvious stains are left. If a large blood spill occurs on carpet, it may need to be shampooed or steam cleaned;

- cover your wounds with a waterproof bandage;

- use condoms with new sexual partners.

For further information please contact your local Public Health Unit, Community Health Centre, or doctor.

September 2001.

\title{
COMMUNICABLE DISEASES, NSW: SEPTEMBER 2001
}

\section{TRENDS}

Reports of influenza began to increase in late June. The majority of cases of influenza diagnosed by major laboratories in NSW have been influenza A, while a small proportion have been influenza $B$.

Following a promising decline in notifications earlier in the year, pertussis has re-emerged (Figure 1). Almost 2,000 cases have been reported this year across the state through to July 2001. The highest rates of infection remain in children of school age. This increase is particularly concerning because, historically, cases rise in spring, which begins this month.
Six cases of Legionnaires disease were reported in July. Three were due to Legionella longbeachae, thought to be transmitted largely by breathing in dust from soil or potting mix. Three were due to Legionella pneumophila, thought to be transmitted largely by breathing in aerosols of contaminated water. These cases were unrelated.

Twenty-four cases of meningococcal disease were notified across the state in July (Table 1), which is in line with seasonal expectations. Hepatitis A notifications increased slightly in July with 21 cases notified. 


\section{FIGURE 1}

\section{REPORTS OF SELECTED COMMUNICABLE DISEASES, NSW, JANUARY 1996 TO JULY 2001 ,}

BY MONTH OF ONSET

These are preliminary data: case counts for recent months may increase because of reporting delays. Laboratory-confirmed cases, except for measles, meningococcal disease and pertussis.

cases

\begin{tabular}{|rr|}
\hline \multicolumn{2}{|c|}{ May-July 01} \\
Male & $48 \%$ \\
$<5$ & $<1 \%$ \\
$5-24$ & $8 \%$ \\
$25-64$ & $84 \%$ \\
$65+$ & $8 \%$ \\
Rural & $89 \%$ \\
\hline
\end{tabular}

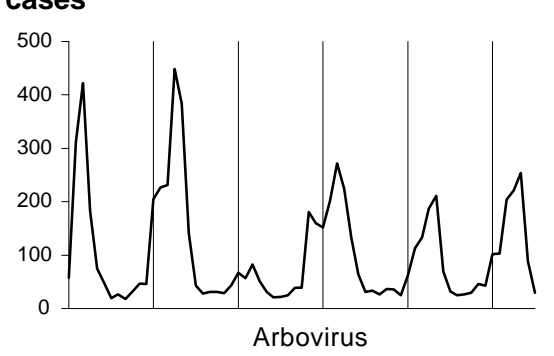

\begin{tabular}{|rc|}
\hline \multicolumn{2}{|c|}{ May-July 01} \\
Male & $70 \%$ \\
$<5$ & $32 \%$ \\
$5-24$ & $22 \%$ \\
$25-64$ & $43 \%$ \\
$65+$ & $3 \%$ \\
Rural & $54 \%$ \\
\hline
\end{tabular}

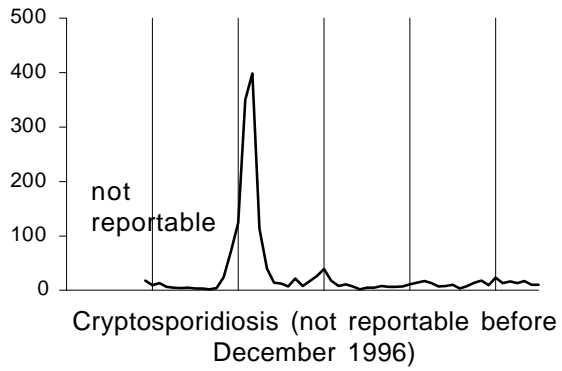

\begin{tabular}{|rr|}
\hline \multicolumn{2}{|c|}{ May-July 01 } \\
Male & $90 \%$ \\
$<5$ & $0 \%$ \\
$5-24$ & $22 \%$ \\
$25-64$ & $77 \%$ \\
$65+$ & $1 \%$ \\
Rural & $13 \%$ \\
\hline
\end{tabular}
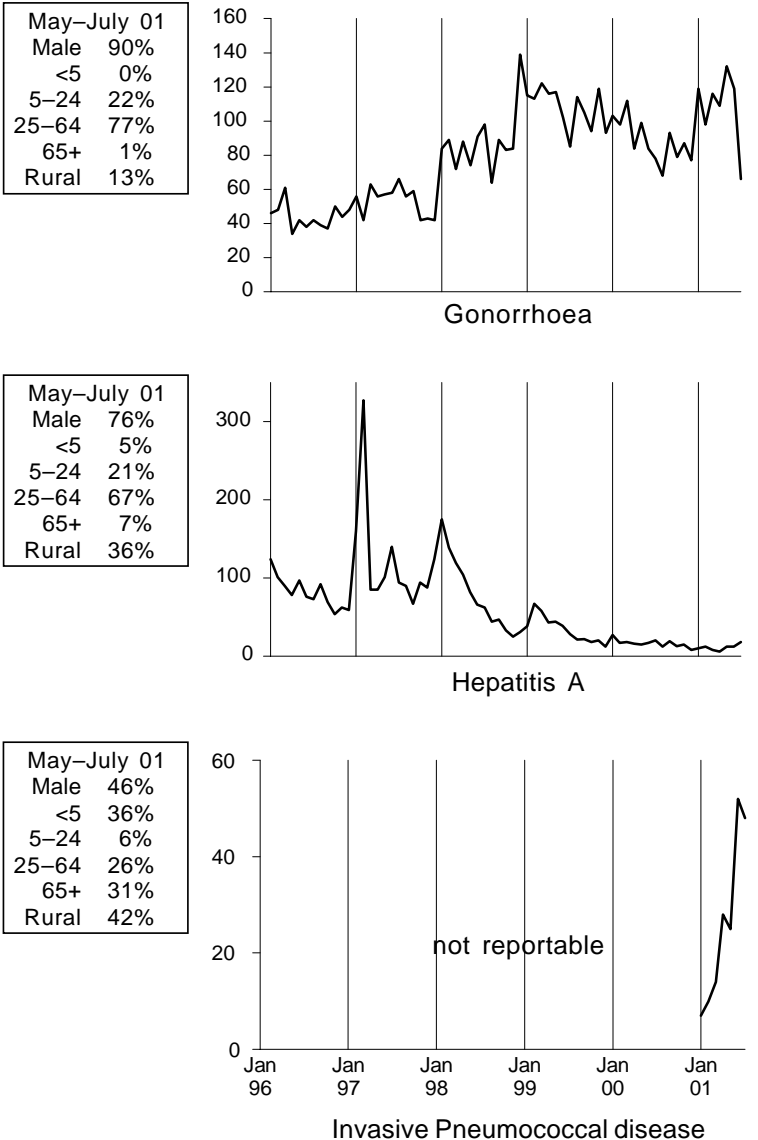
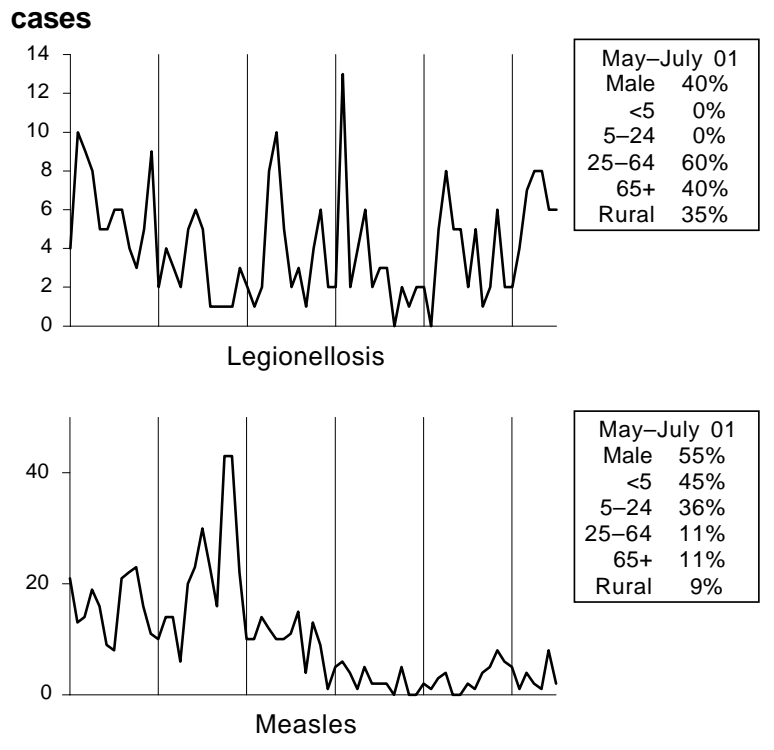

May-July 01 Male $55 \%$

$<5 \quad 45 \%$

$25-64$ 11\%

$65+11 \%$

Rural $9 \%$
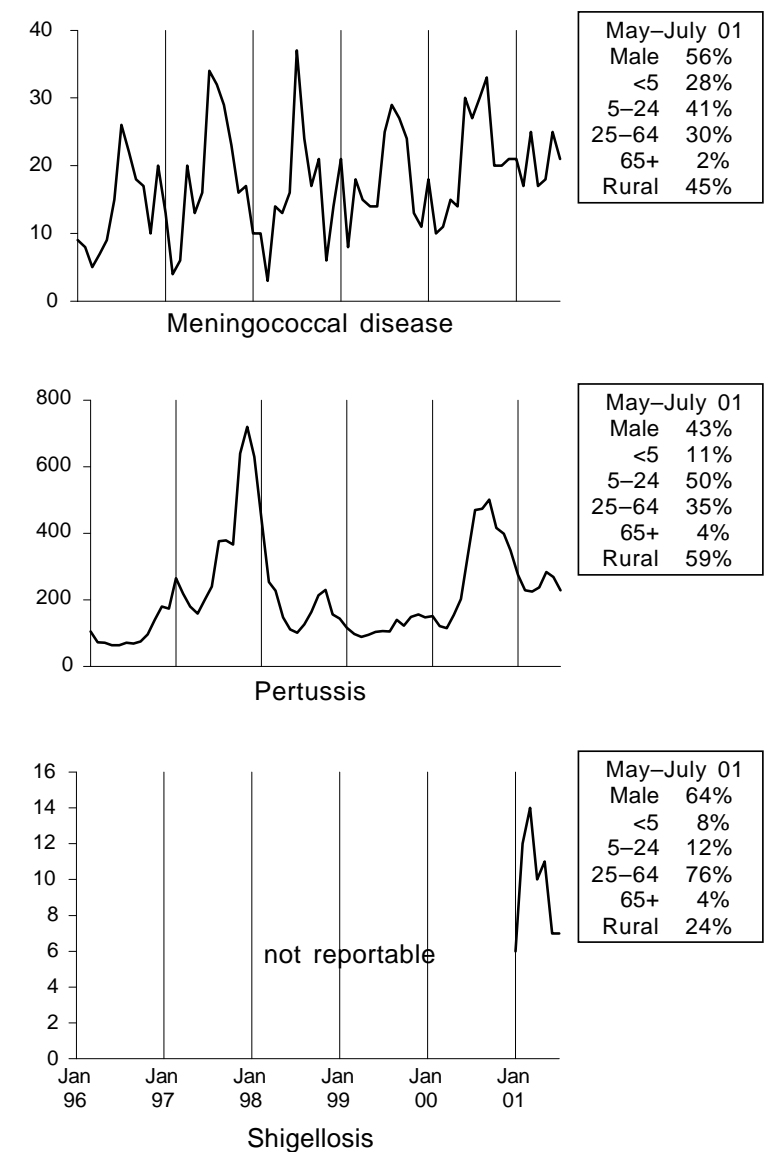


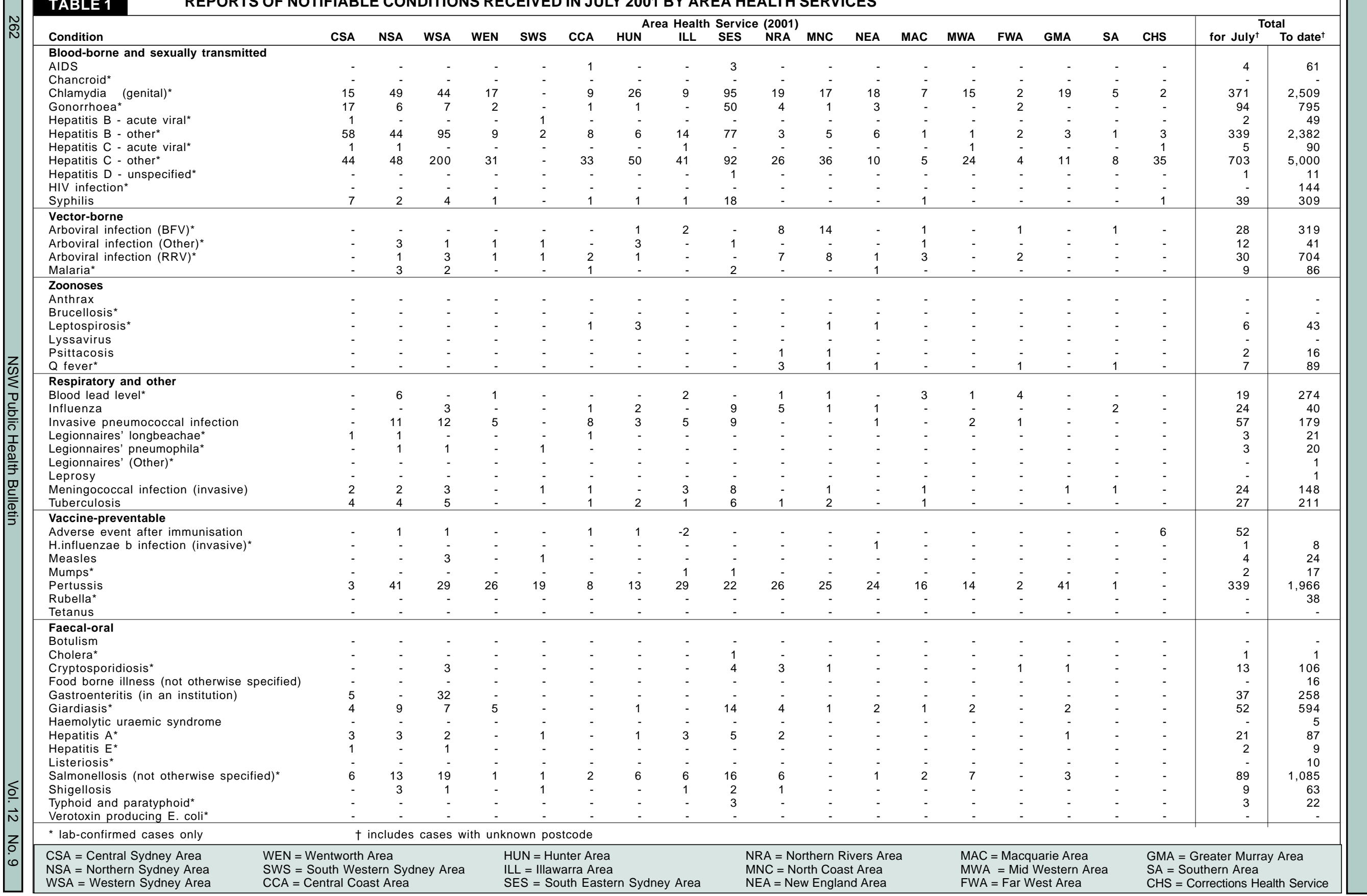

